\title{
Research on the Competitiveness of the Logistics Industry in North China ${ }^{1}$ \\ Hongqi Hui ${ }^{1,}$ a , Yibo Lv ${ }^{2, b}$ * \\ ${ }^{1,2}$ School of Economics and Management, Hebei University of Science and Technology, Shijiazhuang, 050018, China \\ a,blvyibo2015@sina.com
}

Keywords: Regional Logistics Industry; Competitiveness Research; Collaborative development Abstract. In this paper, we use gray correlation analysis technique to study on the competitiveness of the logistics industry in North China. Whereby: Logistics Industry Competitiveness in North China, Tianjin is the strongest, followed by Hebei, Shanxi, Beijing and Inner Mongolia Autonomous Region. According to the competitiveness of the logistics industry in North China analysis results, combined with the actual situation around, the suggestions put forward various provinces in North China logistics industry.

\section{Introduction}

In China, due to the different geographical location, level of economic development, industrial structure, technological level, human resources, government regulation, support and other factors, the level of logistics development in all regions, there is a big difference. Competent authority of the region, logistics companies, only an objective understanding of the relationship between the growth of the regional logistics collaboration, the level of growth and level of cooperation in the region in which there is a science of logistics, proper evaluation, in accordance with the growth of the regional logistics laws, in order to truly promote the region's logistics can sustained and healthy development. Regional logistics support area is an essential element of economic development, competitiveness has become an important part of the region's overall competitiveness. Objective and accurate evaluation of the level of modern logistics development in all regions and the differences with neighboring regional competitiveness is crucial logistics development decisions for each region.

With the implementation of "Beijing, Tianjin and Coordinated Development Plan", Beijing, Tianjin and the joint development of the logistics industry is becoming the focus of attention. In the new period of development of the logistics industry, Beijing, Tianjin and will be collaboration and common development. Adjustment and optimization of Beijing, Tianjin and logistics industry, the logistics industry will break the current pattern of development in North China. This paper will be five provinces in North China (Beijing, Tianjin, Hebei, Shanxi, Inner Mongolia) in the development of the logistics industry competitiveness comparative Research reveals trends laws of the logistics industry in the development of the logistics industry in the various regions and the whole North China to further seek various Countermeasures of the Logistics industry recommendations.

\section{Development of the logistics industry in North China}

Below, we will analyze the five provinces in North China (Beijing, Tianjin, Hebei, Shanxi, Inner Mongolia) logistics industry development.

Modern logistics industry has a service, comprehensive, basic and industrial characteristics of high permeability, its development efficiency on regional economic growth plays a crucial role. Shanxi Province as an important base of energy and raw materials, a series of problems of its pillar industries caused by a single, seriously restricting sustainable economic development. As the country's only provincial domain resource-based economy of comprehensive reform pilot area, Shanxi Province, in the "five" plan to focus on the logistics industry as a pillar industry development and building of the 
center of Taiyuan rapid transit system, speed up the development of third-party logistics, manufacturing enterprises and logistics enterprises to build joint exchange platform to facilitate logistics outsourcing and cooperation, and promote the coordinated development of Shanxi logistics and other industries.

With the national policies and strategic plans were introduced, Inner Mongolia logistics industry has entered a critical period of growth and development and transformation of the shift, continued to slow demand in coal, industrial and other bulk products, cargo and freight turnover decreased under the background of the overall operation of the logistics industry maintained stable development trend, development is still in reasonable range. However, the current logistics corporate services price overall level is not high, low operating efficiency, greater business pressure.

The implementation of "Coordinated Development Plan in Jing-Jin-Ji Region " will speed up the transfer to Beijing logistics industry in Hebei and Tianjin, so Beijing, Tianjin and Hebei logistics industry restructuring, upgrading and coordinated development into the fast lane. Logistics and distribution of resources in Beijing is reasonable. But the rapid development in recent years, making the storage, relative shortage of land and other resources, the urgent need to find space outside. At the same time, Beijing logistics enterprises greater demand for international shipping, but Beijing as the inland cities, apparently facing bottlenecks. The biggest advantage is adjacent to Tianjin Bohai Sea, Tianjin Port which is the backbone of the North's largest bulk cargo port. A relatively large area of Hebei Province, in the land, ports and other aspects have natural conditions, and Beijing, Tianjin, vegetables, food and other supplies, mostly from Hebei, although the existing level logistics industry should be improved, but the development has great potential. Therefore, Beijing, Tianjin, Hebei and according to their own strengths and weaknesses, to seek to achieve regional logistics integration is necessary and feasible.

\section{Analysis of the logistics industry competitiveness in North China}

Using gray relational analysis method, the shape of the curve of the number of columns closeness between them can be formed according to various factors and, for comparison and analysis of dynamic trends, which can be drawn between the two factors or two systems association size metric data (called affinity). In this paper, the theory and method of gray relational analysis of five provinces in North China (Beijing, Tianjin, Hebei, Shanxi, Inner Mongolia) in the development of the logistics industry competitiveness compared. To this end, according to the actual situation of logistics industry in North China, we selected the transportation, storage and postal value added (million) as a measure of the level of development of the logistics industry in various provinces and cities in the number of indicators. As shown in Table 1. As used herein, the statistics from the National Bureau of Statistics (http://data.stats.gov.cn).

Table 1 North China provinces logistics development level indicators (million)

\begin{tabular}{|l|l|l|l|l|l|l|}
\hline Year & Beijin & Tianji & Hebei & Shanxi & Neime & Total \\
\hline 2005 & 403.32 & 277.17 & 790.19 & 375.11 & 361.31 & 2207.10 \\
\hline 2006 & 455.21 & 302.20 & 938.52 & 441.03 & 434.56 & 2571.52 \\
\hline 2007 & 497.55 & 334.67 & 1155.6 & 546.31 & 545.28 & 3079.43 \\
\hline 2008 & 498.92 & 436.37 & 1337.5 & 650.19 & 698.15 & 3621.17 \\
\hline 2009 & 556.64 & 471.01 & 1491.9 & 523.38 & 773.29 & 3816.24 \\
\hline 2010 & 712.01 & 585.37 & 1745.9 & 654.08 & 875.61 & 4572.98 \\
\hline 2011 & 808.95 & 632.10 & 2046.2 & 756.29 & 1040.0 & 5283.59 \\
\hline 2012 & 816.31 & 683.56 & 2212.9 & 847.44 & 1185.3 & 5745.54 \\
\hline 2013 & 883.58 & 725.05 & 2377.5 & 782.49 & 1302.0 & 5976.37 \\
\hline 2014 & 948.01 & 753.19 & 2490.1 & 797.13 & 1379.8 & 6368.35 \\
\hline
\end{tabular}

Source: National Bureau of Statistics

According to statistical data in Table 1, using gray relational analysis theory and method, on the competitiveness of logistics industry in North China were analyzed. 
(1) Determine the female factor time series (reference series) and sub-factors time series (comparison sequence).

Here, set the total value of the logistics industry (five ground transportation, storage and postal added value of the sum of the total value in Table 1) in North China as a base element sequence constituting time series (parent sequences); set points value of the logistics industry in North China (provincial and municipal transportation, storage and postal added value) sequences composed of sub-factors time series (sequence). Female factor time series depicts the global characteristics of the research system (integrity); sub-factors studied time series depicts the various subsystems of the entire system, the overall system-driven.

(2) raw data initialization.

The absolute amount of raw data from the system reflects the original feature, it is not conducive to direct comparative analysis between the various factors that determine the results may bias, and therefore need to be dimensionless initialized. Initialization method used here dimensionless, that index data for 2005 as the base year data are divided by the corresponding data for that year, and the results are shown in Table 2.

Table 2 level logistics industry in North China provinces after initialization index

\begin{tabular}{|c|c|c|c|c|c|c|}
\hline Years & Beijin & Tianji & Hebei & Shanxi & Neime & Total \\
\hline 2005 & 1.00 & 1.00 & 1.00 & 1.00 & 1.00 & 1.00 \\
\hline 2006 & 1.13 & 1.09 & 1.19 & 1.18 & 1.20 & 1.17 \\
\hline 2007 & 1.23 & 1.21 & 1.46 & 1.46 & 1.51 & 1.40 \\
\hline 2008 & 1.24 & 1.57 & 1.69 & 1.73 & 1.93 & 1.64 \\
\hline 2009 & 1.38 & 1.70 & 1.89 & 1.40 & 2.14 & 1.73 \\
\hline 2010 & 1.77 & 2.11 & 2.21 & 1.74 & 2.42 & 2.07 \\
\hline 2011 & 2.01 & 2.28 & 2.59 & 2.02 & 2.88 & 2.39 \\
\hline 2012 & 2.02 & 2.47 & 2.80 & 2.26 & 3.28 & 2.60 \\
\hline 2013 & 2.16 & 2.44 & 2.97 & 2.09 & 3.60 & 2.71 \\
\hline 2014 & 2.35 & 2.72 & 3.15 & 2.13 & 3.82 & 2.89 \\
\hline
\end{tabular}

(3) Mother sequence with the sequence of the absolute value of the difference is calculated for each time point, the results shown in Table 3

Table 3 each point in time the parent sequence with sequences absolute difference

\begin{tabular}{|c|c|c|c|c|c|}
\hline Years & Beijin & Tianji & Hebei & Shanxi & Neimeng \\
\hline 2005 & 0.00 & 0.00 & 0.00 & 0.00 & 0.00 \\
\hline 2006 & 0.04 & 0.08 & 0.02 & 0.01 & 0.03 \\
\hline 2007 & 0.17 & 0.19 & 0.06 & 0.06 & 0.11 \\
\hline 2008 & 0.40 & 0.07 & 0.05 & 0.09 & 0.29 \\
\hline 2009 & 0.35 & 0.03 & 0.16 & 0.33 & 0.41 \\
\hline 2010 & 0.30 & 0.04 & 0.14 & 0.33 & 0.35 \\
\hline 2011 & 0.38 & 0.11 & 0.20 & 0.37 & 0.49 \\
\hline 2012 & 0.58 & 0.13 & 0.20 & 0.34 & 0.68 \\
\hline 2013 & 0.55 & 0.27 & 0.26 & 0.62 & 0.89 \\
\hline 2014 & 0.54 & 0.17 & 0.26 & 0.76 & 0.93 \\
\hline
\end{tabular}

(4) Mother sequences extracted maximum and minimum values with the sequence of the absolute value of the difference between 0.93 and 0 , respectively

(5) Ask each parent sequence correlation coefficient on point with the promoter sequence (here taken to distinguish factor of 0.5), and the results are shown in Table 4.

Seeking various sub-sequence of the parent sequence of related degree. Correlation coefficient reflecting the degree of association between each data point. Correlation coefficients more decentralized so that the information we are concerned, it is difficult comparative analysis. Because we will each sub-sequence correlation coefficients together, form a single value. We averaged each sub-sequence correlation coefficient, which represents the total associated with Tara sequences and promoter sequences. The results are shown in Table 4. 
Table 4 on each point in the sequence with the sequences mother correlation coefficient

\begin{tabular}{|c|c|c|c|c|c|}
\hline Years & Beijin & Tianji & Hebei & Shanxi & Neimeng \\
\hline 2005 & 1.00 & 1.00 & 1.00 & 1.00 & 1.00 \\
\hline 2006 & 0.92 & 0.85 & 0.96 & 0.99 & 0.93 \\
\hline 2007 & 0.74 & 0.71 & 0.88 & 0.89 & 0.81 \\
\hline 2008 & 0.54 & 0.88 & 0.90 & 0.83 & 0.61 \\
\hline 2009 & 0.57 & 0.94 & 0.75 & 0.58 & 0.53 \\
\hline 2010 & 0.60 & 0.92 & 0.77 & 0.59 & 0.57 \\
\hline 2011 & 0.55 & 0.81 & 0.70 & 0.55 & 0.49 \\
\hline 2012 & 0.45 & 0.78 & 0.70 & 0.58 & 0.41 \\
\hline 2013 & 0.46 & 0.63 & 0.64 & 0.43 & 0.34 \\
\hline 2014 & 0.46 & 0.73 & 0.64 & 0.38 & 0.33 \\
\hline Related degree & 0.63 & 0.82 & 0.79 & 0.68 & 0.60 \\
\hline Sorted Results & 4 & 1 & 2 & 3 & 5 \\
\hline
\end{tabular}

\section{Conclusions and Recommendations}

According to the association of various sub-sequence of the parent sequence, in descending order, the result is:North China's logistics industry is the most competitive in Tianjin, followed by Hebei, Shanxi, Beijing and Inner Mongolia, the shown in Table 4.

First, Tianjin in North China as the competitiveness of the logistics industry in the development of strong, should play an important role in the area of logistics integration.

Second, Hebei vast territory, the level of the absolute value of the logistics development indicators (transport, storage and postal added value) always is maintain the leading position, but the competitiveness is still inadequate. Hebei is necessary to improve their level of logistics development, but also to do a non-capital function Beijing, Hebei region to ease and acceptance.

Third, the competitiveness of the logistics industry in Shanxi in the middle level, is need to continue to improve the competitiveness of the logistics industry.

Fourth, Beijing logistics industry competitiveness is relatively weak, not only to improve their level of logistics development, but also to ease the related non-capital function (including associated logistics).

Fifth, Inner Mongolia logistics industry competitiveness, in North China is the most weak. Improve the competitiveness of the logistics industry in Inner Mongolia, will be a long-term task.

\section{References}

[1] Julong Deng, gray control system [M], Huazhong University of Science Press, 1997: 357-362.

[2] Ai-dong WU, An Empirical Study of Cooperative Development Between Logistics Industry and Economy in Jing-Jin-Ji Region, Journal of Tianjin University of Commerce, 2014,(5).

[3] Sisi Ma, low carbon Logistics Development in Jing-Jin-Ji Region, Jiangsu Science \& Technology Information, 2014,(2).

[4] Liqin Gu, Comprehensive Evaluation on Regional Logistics Competitiveness: An Empirical Study on Six Provinces in Central China. logistics and technology, 2015,(2)

[5] Information on http:// data.stats.gov.cn 